\title{
Seedling salt tolerance in tomato
}

\author{
Junming Li $\cdot$ Lei Liu $\cdot$ Yuling Bai \\ Pujuan Zhang $\cdot$ Richard Finkers $\cdot$ Yongchen Du • \\ Richard G. F. Visser · Adriaan W. van Heusden
}

Received: 12 August 2010/ Accepted: 30 November 2010/Published online: 19 December 2010

(C) The Author(s) 2010. This article is published with open access at Springerlink.com

\begin{abstract}
Soils with higher concentrations of salt are becoming more and more a constraint for many crops to obtain high yields. Wild tomato species, adapted to adverse environments, are a potential reservoir for genes underlying quantitative trait loci (QTL) related to salt tolerance in tomato. In this study two introgression line (IL) libraries derived from two different wild species, Solanum pennellii LA716 and Solanum lycopersicoides LA2951, were used to identify QTLs for salt tolerance in the seedling stage. In the $S$. pennellii IL library, four major QTLs were identified on chromosomes 6, 7 and 11. In the $S$. lycopersicoides IL library, six major QTLs were discovered which are located on chromosomes 4, 6, 9 and 12. Co-localization of QTLs on chromosome 6 in the two IL libraries and previously
\end{abstract}

J. Li $(\bowtie) \cdot$ L. Liu · P. Zhang · Y. Du

Institute of Vegetables and Flowers, Chinese Academy of Agricultural Sciences, No. 12 Zhongguancun Nandajie, Haidian District, Beijing 100081, China

e-mail: junmingli@mail.caas.net.cn

J. Li · Y. Bai · R. Finkers · R. G. F. Visser .

A. W. van Heusden

Wageningen UR Plant Breeding, Wageningen University \& Research Center, P.O. box 386, Wageningen 6700 AJ, The Netherlands

\section{J. Li}

Graduate School Experimental Plant Sciences, Wageningen University \& Research Center, P.O. box 386, Wageningen 6700 AJ, The Netherlands reports hinted that this locus might be conserved in the tomato crop. Three $S$. pennellii ILs (IL6-2, IL7-1 and IL7-5) harboring QTLs on chromosome 6 and 7 were crossed. Semi-dominance and dominance were shown for these three QTLs, and non-additive and epistatic interactions between them were observed.

Keywords Tomato - Seedling - Salt tolerance . Solanum pennellii $\cdot$ Solanum lycopersicoides

\section{Introduction}

The level of salt tolerance of crops has recently received a lot of attention due to the increase of salinised cultivated lands throughout the world. This increase is caused by both natural phenomena and human activities (Ghassemi et al. 1995). Secondary salinisation of cultivated lands is caused by improper agricultural practices such as the use of too much chemical fertilization and/or inadequate irrigation management. Furthermore, land degradation caused by secondary salinisation is getting more and more a problem (Ghassemi et al. 1995; Zhang et al. 2007).

In addition, competition for available fresh water resources has resulted in development of irrigation with saline water (Ghassemi et al. 1995). Tomato, which is a worldwide economically important crop and adapted to various climates, is also suffering from salinised soils. Too much salt in the soil results 
in a reduced plant development and growth and subsequently in a lower yield. Most modern tomato cultivars are already sensitive to moderate levels of salt in the soil (Rush and Epstein 1976; Costa et al. 1990; Hassan et al. 1990; Saranga et al. 1992; Foolad and Lin 1997), although a large amount of tomatoes are cultivated in saline areas (Burns et al. 1990; Foolad 1997). China is one of the largest producers for both the fresh and the processing tomato market (http://www.fas.usda.gov) and in China the majority of processing tomatoes is grown in salinised soils in north-west regions (Mao et al. 2002). Sixty percent of the processing tomatoes in China are transplanted seedlings and $40 \%$ is sown directly. Salinity slows down tomato shoot growth and the growth of younger seedlings; the higher the saline concentration the larger the reduction in shoot growth (Cuartero and Fernandez-Munoz 1999; Flowers 2004; Cuartero et al. 2006). The tomato response to salt stress is differently regulated in different development stages (Costa et al. 1990; Saranga et al. 1992; Foolad 2004). This has also been reported in other crop species (Greenway and Munns 1980; Shannon 1985; Maas 1986; Lauchli and Epstein 1990; Johnson et al. 1992; Foolad et al. 1999). During flowering and fruit setting, tomato plants are able to withstand $\mathrm{NaCl}$ concentrations which are sufficient to kill them in the seedling stage (Elshourbagy and Ahmed 1975). This makes it also important that tomatoes are more salt tolerant in their seedling stage. Transplanting of seedlings with higher salt tolerance guarantees a better performance and a faster growth.

Accessions of wild species adapted to dry or seashore regions have been evaluated for salt tolerance and some accessions of $S$. pimpinellifolium, S. peruvianum, S. cheesmaniae, S. habrochaites, S. chmielewskii and S. pennellii, showed certain levels of salt tolerance (Rush and Epstein 1976; Costa et al. 1990; Hassan et al. 1990; Saranga et al. 1992; Foolad and Lin 1997). To identify the chromosomal regions associated with a stable salt tolerance, molecular markers and quantitative trait loci (QTL) analyses have been used. Seven QTLs, on chromosomes 1, 2, 3, 7, 8, 9 and 12, for better seed germination under saline conditions were identified in various segregating populations derived from S. pennellii LA716 and S. pimpinellifolium LA722. Three stable QTLs causing salt tolerance during the vegetative growth were identified on chromosomes 3, 5 and 9, which were originated from the wild accession LA722 (Foolad 2004). Other QTLs were identified for fruit-related traits under salt stress (Monforte et al. 1996, 1997a, 1997b, 1999). Limited research has been done to identify QTLs for salt tolerance in terms of yield (Bretó et al. 1994; Villalta et al. 2007).

Introgression lines (IL) are produced by crossing a well known cultivar with an exotic species followed by repeated backcrossing and marker selection. Ideally, a derived line has only a single introgression and the complete library of introgression lines represents the entire genome of the wild parent. A big advantage of IL populations is that they can be evaluated in different environments and laboratories since they are genetically homozygous and in principle an unlimited number of seeds can be obtained (Eshed and Zamir 1995; Gur and Zamir 2004). The effect of a single QTL as well as of interactions between QTLs can be efficiently studied (Gur and Zamir 2004; Christopher and Leonie 2009). Currently five IL populations have been described in tomato (Eshed and Zamir 1995; Monforte and Tanksley 2000; Canady et al. 2005; Francis et al. 2001; Finkers et al. 2007). Among these five populations, the $S$. pennellii LA716 IL library has been extensively explored to identify QTLs for several traits related to biotic stress and fruit quality (Eshed and Zamir 1995; Astua-Monge et al. 2000; Rousseaux et al. 2005; Tieman et al. 2006). However, this S. pennellii accession also has a lot of potential for studies on abiotic stress but only few reports have been published. In one of them, five loci, conferring salt tolerance during seed germination, have been identified using a $F_{2}$ population (Foolad et al. 1997) but salt tolerance in the seedling stage was not studied. Two IL populations, derived from S. pennellii LA716 and S. lycopersicoides LA2951 have been screened for salt tolerance in seedlings in this study. A number of QTLs have been identified in both populations and the value of these QTLs results is being discussed in this paper.

\section{Materials and methods}

Plant material

Two introgression libraries were used for screening seedlings under saline conditions. One of them was 
the $S$. pennellii IL library LA716 in the background of S. lycopersicum cv. M82 (Eshed and Zamir 1995). LA716 is a self-compatible, homozygous green fruited, indeterminate accession and M82 a red fruited, determinate, processing-type tomato. The population is composed of a primary set of 52 ILs with a representation of the $S$. pennellii genome in as few as possible lines. A further 26 sub-lines are available for certain regions. All ILs were screened together with the parental line M82 in six independent experiments. The second IL population is the S. lycopersicoides LA2951 in the background of S. lycopersicum VF36 (Canady et al. 2005). The primary set is 56 ILs and a secondary set of 34 sublines can be used for improving map resolution in certain regions. LA2951 is a tomato-like nightshade species and is a self-incompatible, homozygous green fruited, indeterminate accession. VF36 is a red fruited, determinate, beef-type tomato. Of the total library of 90 lines only 77 lines were available and screened in four independent experiments, some of these lines were sterile or did not produce enough seeds. Sterility caused by homozygous introgressions make some lines of the $S$. lycopersicoides IL population difficult to maintain. This applies especially for three lines (LA4242, LA4277 and LA4282) and in a lesser extend for another twelve lines where only very few seeds are produced (LA4234, LA4263, LA4266, LA4236, LA3875, LA4253, LA4300, LA4260, LA4270, LA4276, LA4278 and LA4282)(Canady et al. 2005). When enough seeds could be obtained after self pollination in these fifteen ILs the lines with homozygous introgressions were screened although they have been originally categorized as heterozygous introgressions (Canady et al. 2005).

Three lines (IL6-2, IL7-1 and IL7-5) from the IL population of $S$. pennellii LA716 with a higher salt tolerance in seedlings were crossed to M82 and pair wise crossed to generate introgression line hybrids (ILHs).

Evaluation of salt tolerance in the seedling stage

Salt tolerance in seedlings was measured according to a slightly modified method of Foolad and Chen (1999). Seeds were surface sterilized with $0.5 \%$ $\mathrm{NaOCl}$ solution, rinsed with water and sown in pots containing a 1:1:1 peat-perlite-vermiculite (v/v) medium. Eight seedlings with four fully developed true leaves were transferred into hydroponic tanks after their roots were washed to remove attached growing medium. Each tank $(68 \times 40 \times 28 \mathrm{~cm})$ contained 20L of half-strength modified Hoagland solution (Epstein 1972) and plants were grown in a greenhouse with average day and night temperatures of approximately $20-25^{\circ} \mathrm{C}$ and $15-18^{\circ} \mathrm{C}$. The hydroponic solutions were continuously and vigorously aerated. The first increase of salts $(50 \mathrm{mM} \mathrm{NaCl}+$ $5 \mathrm{mM} \mathrm{CaCl}_{2}$ ) was added four days after transplanting and every day the concentration was enhanced with $50 \mathrm{mM} \mathrm{NaCl}+5 \mathrm{mM} \mathrm{CaCl} 2$ to achieve a final concentration of $700 \mathrm{mM} \mathrm{NaCl}+70 \mathrm{mM} \mathrm{CaCl} 2$. The solution with the final concentration was changed weekly. From the third week on, after the final salt concentration was reached, the plants were evaluated.

Each plant was visually evaluated using a scale of 0-9 (Table 1). The data were transformed into percentage performance by multiplying the average value with 11 to get survival performance (the average value is calculated and divided in nine classes; $0-1$, $1-2, \ldots$ 8-9). For each genotype, a mean value of performance percentage $(\%)$ was determined as the average of the performance values of all individuals within the genotype.

\section{Nomenclature}

We name the identified QTLs as follows: Salt Tolerance from S. pennellii QTL (Stpq) or Salt Tolerance from S. lycopersicoides QTL (Stlq) followed by the number of the chromosome. If QTLs are located on the same chromosome, we used the letters a, b, c.

\section{Statistic analysis}

All statistical analyses were performed using SPSS 13.0. Phenotypic data were analyzed using the general linear model (GLM). The mean value of performance percentage $(\%)$ was calculated using the following models: percentage performance $(\%)=$ constant + genotype + experiment + genotype $\times$ experiment. For QTL mapping, each IL was compared to the parental control M82 or VF36. If there was a significant difference from the reference genotype M82 or VF36, a QTL was assumed to be present in the introgression line. 
Table 1 Evaluation parameters of plants under salt stress

\begin{tabular}{ll}
\hline Score & Phenotypes of plant \\
\hline 0 & Dead plant with all leaves and stems damaged \\
1 & Almost all of the leaves damaged \\
2 & $\begin{array}{c}\text { Most of the leaves damaged with obvious drying of } \\
\text { leaves }\end{array}$ \\
3 & Complete curled and severely damaged dry leaves \\
4 & Complete curled and moderate damaged dry leaves \\
5 & Complete curled leaves and slight damages of some of \\
& the leaves \\
7 & Complete curled leaves \\
8 & Green plants with moderate inward curled leaves \\
9 & Healthy plant with no visible symptoms of salt damage \\
& (e.g., chlorosis, necrosis, wilting)
\end{tabular}

For further studies on the genetics of certain identified QTLs from S. pennellii LA716, ILs were crossed and the analytical method described previously by Gur and Zamir (2004) and Semel et al. (2006) was followed. If an IL was significantly different from M82 and the ILH (the product of the cross) had a score in between the IL and M82, there are three possibilities: (i) If the score of the ILH was significantly different from the IL but not from M82, it was considered recessive; (ii) If the ILH differed from both parents or did not differ from either of them, it was considered as additive; and (iii) If the ILH differed from M82 but not from IL, the QTL was considered as dominant with a further refinement that when the ILH was significantly higher or lower than both its parents, it was considered as overdominant.

To estimate the interactions between QTLs, a modified method (Eshed and Zamir 1996) was followed. The lines in each test were M82, ILHa $(\mathrm{IL}(\mathrm{a}) \times \mathrm{M} 82)$, ILHb (IL(b) $\times$ M82) and ILHab (IL(a) $\times \operatorname{IL}(b))$. The mean value of performance percentage of introgressed segment was calculated by the general linear model (GLM). The interaction effect was estimated as ((M82 + ILHab) - (ILHa + $\mathrm{ILHb}$ ) and its significance was determined by an $F$ test. The complete additivity of the QTL was estimated as ((ILHa - M82) $+($ ILHb - M82)). The expected values were tested against the observed values and the regression line was tested against a null hypothesis of complete additivity (expecte$\mathrm{d}=$ observed or H0: $\beta=1$ vs. H1: $\beta<>1$ ).

\section{Results}

Evaluation of S. pennellii LA716 IL population

The performance value was used to evaluate salt tolerance in seedlings over six independent experiments in 2 years. A higher performance value indicates a higher level of salt tolerance. During the gradual increase of the salt concentration leaf chlorosis and wilting became visible. The mean experiment performance (\%, see Table 3 ) varied from 33.9 to $53.1 \%$ with the exception of experiment 3 , which showed only $14.5 \%$. The correlations between experiments were low $(r=0.25-0.36)$ and only significant correlations were present between experiments 1,2 and 6 , as well as between experiments 3 and 4 . Only experiments 1,2 and 6 were further used, since experiment 3 and 4 were executed in the rainfall season which might have had an influence on the conditions in the greenhouse. The performance rate of the different introgression lines in the three experiments, varied from 15.3 to $64.6 \%$ and the control M82 had a value of $31.9 \%$. Leaving out experiments 3 and 4 made the significance of the QTLs higher but the direction of the effects remained the same. The performance rate of nine lines was lower than M82, with IL6-3 as the lowest (15.3\%). sixteen lines (IL1-1-3, IL1-4-18, IL2-1, IL4-3-2, IL62, IL7-1, IL7-4-1, IL7-5, IL7-5-5, IL9-1-2, IL10-1-1, IL11-1, IL11-2, IL11-4, IL12-2 and IL12-3) performed significantly better than M82 (Table 2).

The $S$. pennellii LA716 IL population consists of primary lines and sub-lines (Eshed and Zamir 1995). Some lines have completely or partly overlapping introgressions and can thus be considered as repetitions in the experiment. Potentially they also allow a more precise map position determination based on the subdivided 107 "bins" (Pan et al. 2000). A QTL was considered only when ILs presented a consistent performance over the selected three experiments. For instances, IL7-1 had a better performance under salt stress in all three experiments with border markers TG438 and TG499. This result was confirmed in the overlapping IL7-2, which is also salt tolerant $(43.7 \%$, $P=0.86)$. We refer to this QTL as Stpq7a, which is located in bin 7-H. IL7-4-1, IL7-5 and IL7-5-5 have overlapping introgressions in the region flanked by the markers TG418A and TG272A and no overlap with IL7-1. All of these three lines have a significant 
Table 2 The percentage performance (\%) of lines from the S. pennellii LA716 IL population with a significant difference as compared to the parent line $S$. lycopersicum M82 under salt stress

\begin{tabular}{|c|c|c|c|c|c|c|}
\hline \multirow[t]{2}{*}{ IL line } & \multirow[t]{2}{*}{ QTL } & \multirow{2}{*}{$\begin{array}{l}\text { Flanking } \\
\text { markers }\end{array}$} & \multicolumn{3}{|c|}{ Percentage performance in each experiment $(\%)$} & \multirow{2}{*}{$\begin{array}{l}\text { Mean } \\
\text { value }(\%)\end{array}$} \\
\hline & & & 1 & 2 & 6 & \\
\hline IL6-2 & Stpq6 & TG365-TG292 & 72.7 & 51.5 & 69.4 & $64.6 * *$ \\
\hline IL7-1 & Stpq7a & TG438-TG499 & 54.6 & 45.5 & 57.9 & $52.7 * *$ \\
\hline IL7-4-1 & Stpq7b & СТ52-CT158 & 51.5 & 39.4 & 61.4 & $50.8 * *$ \\
\hline IL11-1 & Stpq11 & TG557-TG523 & 39.4 & 39.4 & 69.3 & $49.4 *$ \\
\hline M82 & - & - & 27.3 & 27.3 & 41.1 & 31.9 \\
\hline
\end{tabular}

The average is calculated over three experiments using a GLM procedure and Dunnett test. Flanking markers are according to Eshed and Zamir (1995)

* Significantly different at 0.05 level

** Significantly different at 0.01 level

better performance under salt stress and it was concluded that there must be another QTL located on chromosome 7, Stpq7b located in bin 7-B.

A total of four major QTLs (see Table 2) located respectively on chromosome 6,7 and 11 were identified. More detailed marker studies are needed to know the exact locations and number of introgressions.

Evaluation of the S. lycopersicoides LA2951 IL population

Four independent experiments over 2 years were done to measure salt tolerance in the S. lycopersicoides LA2951 IL population. The mean experiment performance $(\%)$ varied from 24.2 to $58.5 \%$. The correlations between the different experiments were not high ( $r=0.33-0.50)$ and finally only the three experiments with a significant correlation were used for the analysis (experiments 2, 3 and 4). Leaving out one experiment only changed the significance level of the QTLs like in the S. pennellii LA716 population.

The cultivar VF36 had a performance of $48.2 \%$. The response to the salt treatment varied among the different ILs in the range from 32.9 to $69.7 \%$. Exceptions were the two ILs, LA4244 and LA4314, with an extremely low performance rate of 19.8 and $6.1 \%$ respectively. Seven lines had a significant higher salt tolerance (Table 3). The S. lycopersicoides ILs cover the tomato genome in 68 "bins" (Canady et al. 2005). After analyzing the results six QTLs (Stlq4, Stlq6, Stlq9a, Stlq9b, Stlq12a and
Stlq12b) were robust (Table 3). Either their effects were confirmed in lines with overlapping introgressions or the effect was clearly present in the three independent experiments. For instance, line LA4245 contains a homozygous introgression on chromosome 4 and was persistent salt tolerant in the three experiments. Line LA4277 has a partly overlapping heterozygous introgression on chromosome 4 and was not salt tolerant in two out of three experiments (Fig. 1a). In case of one dominant QTL it must be located in the middle of chromosome 4 (Stlq4), which is located in bin 4-C. Another example is LA4253, with a heterozygous (see M\&M) introgression on chromosome 6, this IL showed salt tolerance in three experiments indicating a single QTL (Stlq6, bin 6-A). The homozygous introgression on the top of chromosome 9 in LA4242 is also present in lines LA4268 and LA4270. LA4270 showed a significant higher salt tolerance over three independent experiments and LA4268 had a high performance in the only experiment where it was evaluated. Hence it is likely that QTL Stlq9a is located in the overlap of the introgressions of LA4242 and LA4268 (or LA4270), located near the top of Chromosome 9 in bin 9-B. However LA4271 is also salt tolerant and we must presume another QTL (Stlq9b in bin 9-E) located in the overlap of the introgressions of LA4270 and LA4271 but not in the introgression of LA4272. This means that two QTLs might present in line LA4270 but their effects are not additive. In a similar way two QTLs Stlq12a in bin 12-A and Stlq12b in bin 12-E could be identified on chromosome 12 . 
Table 3 The percentage performance (\%) of lines from the S. lycopersicoides LA2951 IL population with a significant difference as compared to the parent line $S$. lycopersicum VF36 under salt stress

\begin{tabular}{|c|c|c|c|c|c|c|c|c|}
\hline \multirow[t]{2}{*}{ IL } & \multirow[t]{2}{*}{ QTL } & \multirow[t]{2}{*}{ Chromosome } & \multirow{2}{*}{$\begin{array}{l}\text { Flanking } \\
\text { markers }\end{array}$} & \multicolumn{3}{|c|}{ Percentage performance in each experiment $(\%)$} & \multirow{2}{*}{$\begin{array}{l}\text { Mean } \\
\text { value }(\%)\end{array}$} & \multirow{2}{*}{$\begin{array}{l}\text { Homozygous } \\
\text { line }\end{array}$} \\
\hline & & & & 2 & 3 & 4 & & \\
\hline LA4245 & Stlq4 & 4 & TG180-TG68 & 60.0 & 70.5 & 60.2 & 63. $6 * *$ & Yes \\
\hline LA4253 & Stlq6 & 6 & TG297-Adh-2 & 65.0 & 70.5 & 59.1 & $64.8 * *$ & Yes \\
\hline LA4270 & Stlq9a & 9 & TG105B-TG424 & 54.6 & 64.8 & 64.6 & $61.0 * *$ & Yes \\
\hline LA4271 & Stlq9b & 9 & TG186-CT220 & 63.6 & 68.2 & 59.1 & $63.6 * *$ & Yes \\
\hline LA4313 & Stlq12a & 12 & TG180-TG68 & 55.8 & 70.4 & 63.6 & $63.3 * *$ & Yes \\
\hline LA4282 & Stlq12a & 12 & TG180-TG111 & 75.8 & 60.2 & 50.0 & $61.0 *$ & Yes \\
\hline LA4284 & Stlq12b & 12 & CT156-TG473 & 63.6 & 70.5 & 59.1 & $64.4 * *$ & Yes \\
\hline VF36 & - & - & - & 46.6 & 53.5 & 44.6 & 48.2 & Yes \\
\hline
\end{tabular}

The average is calculated over three experiments using a GLM procedure and Dunnett test. Flanking markers were based on Canady et al. (2005) and TGRC (http://tgrc.ucdavis.edu/)

* Significantly different at 0.05 level

** Significantly different at 0.01 level

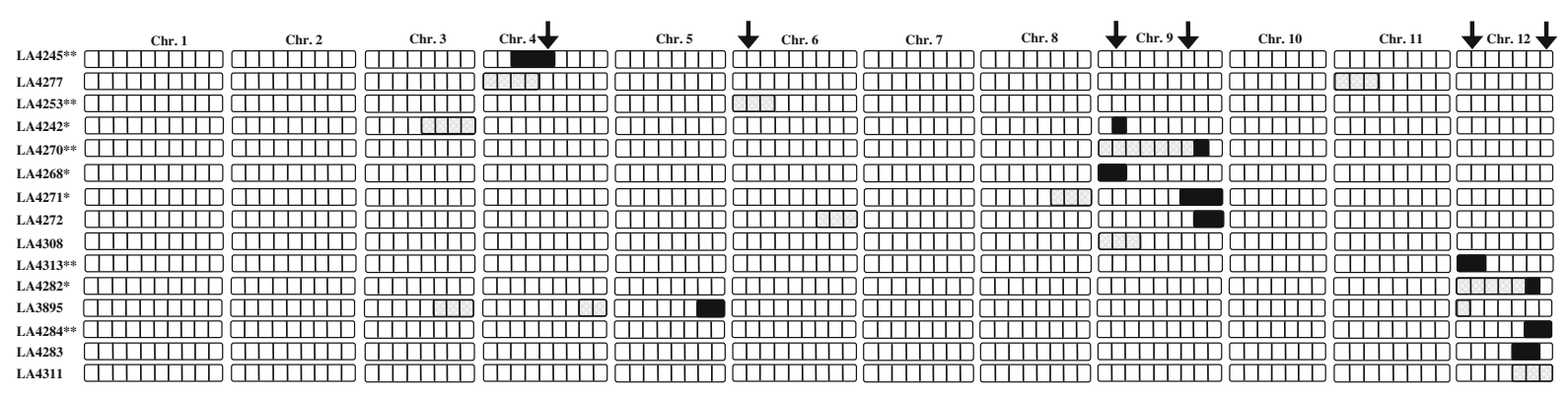

Fig. 1 Columns indicate chromosomes and rows indicate introgression lines (ILs). Solid and shaded segments show homozygous and heterozygous introgressions in the IL respectively based on Canady et al. (2005) Thirteen out of 77 ILs from $S$. lycopersicoides LA2951 showed significant

Genetic analysis of some QTLs derived from $S$. pennellii IL population

To study further genetic effects of the identified QTLs on salt tolerance, three ILs (IL6-2, IL7-1 and IL7-5) of $S$. pennellii LA716 were selected that harbor three QTLs with relatively large effects, namely Stpq6, Stpq7a and Stpq7b. To study the dominance, crosses were made to generate single hybrids (ILH) between each IL and M82. Salt tolerance of these hybrids and their parents was evaluated in four independent experiments. Under salt stress hybrids of ILs and M82 showed in all four experiments significantly better performance than M82, suggesting dominance effects of the investigated QTLs (Fig. 2). Complete dominance was differences $(* P<0.05$ and $* * P<0.01$ ) as compared to the susceptible control $S$. lycopersicum VF36 under salt stress. Their overlapped ILs used in the screening was also presented. Black arrows indicate the most likely location of the confirmed QTLs through three experiments and/or their overlapping ILs

observed for Stpq7a as the hybrid (ILH) and its parental IL7-1 had a similar performance. While, Stpq $7 \mathrm{~b}$ and Stpq6 were semi-dominant since ILHs were closer to ILs than to (IL + M82)/2.

Interactions of QTLs were studied by crossing ILs of three combinations (IL6-2 $\times$ IL7-1, IL6-2 $\times$ IL75 and IL7-1 $\times$ IL7-5) and double hybrids were tested for salt tolerance in four independent experiments. Double hybrids of IL6-2 $\times$ IL7-1 and IL6-2 $\times$ IL7-5 showed a similar performance to their ILHs, indicating a non-additive effect of these three QTLs (Fig. 3). The results also show that Stpq7a and Stpq7b do not extra contribute to salt tolerance if Stlq6 is present (Fig. 3). In contrast, the performance of the double hybrid of IL7-1 $\times$ IL7-5 was significantly lower than that of the corresponding single hybrids (ILHs), 
Fig. 2 Mean value of percentage performance (\%) of the lines IL6-2, IL71 and IL7-5 with a homozygous introgression, the recurrent parent and their hybrid * significantly different at 0.05 level; ** significantly different at 0.01 level

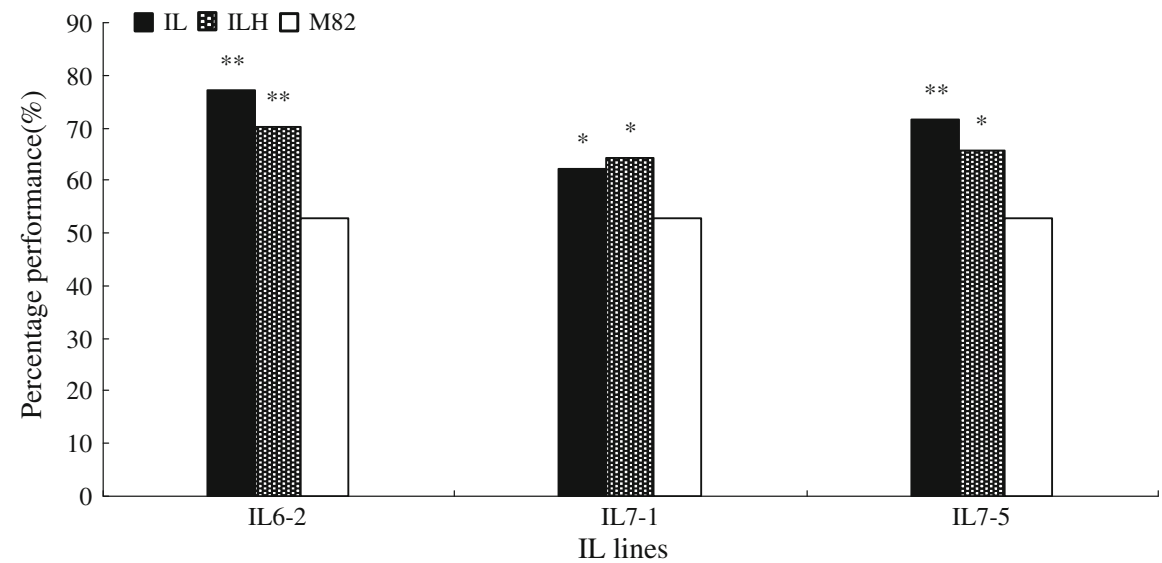

Fig. 3 Mean value of percentage performance $(\%)$ of ILHa $($ M82 $\times$ ILa) (first bar from the left), $\mathrm{ILHb}(\mathrm{M} 82 \times \mathrm{ILb})($ second bar) and the lines with both introgressions (ILa x ILb) (third bar), and the recurrent parent M82 (the fourth column).

** significantly different at 0.01 level

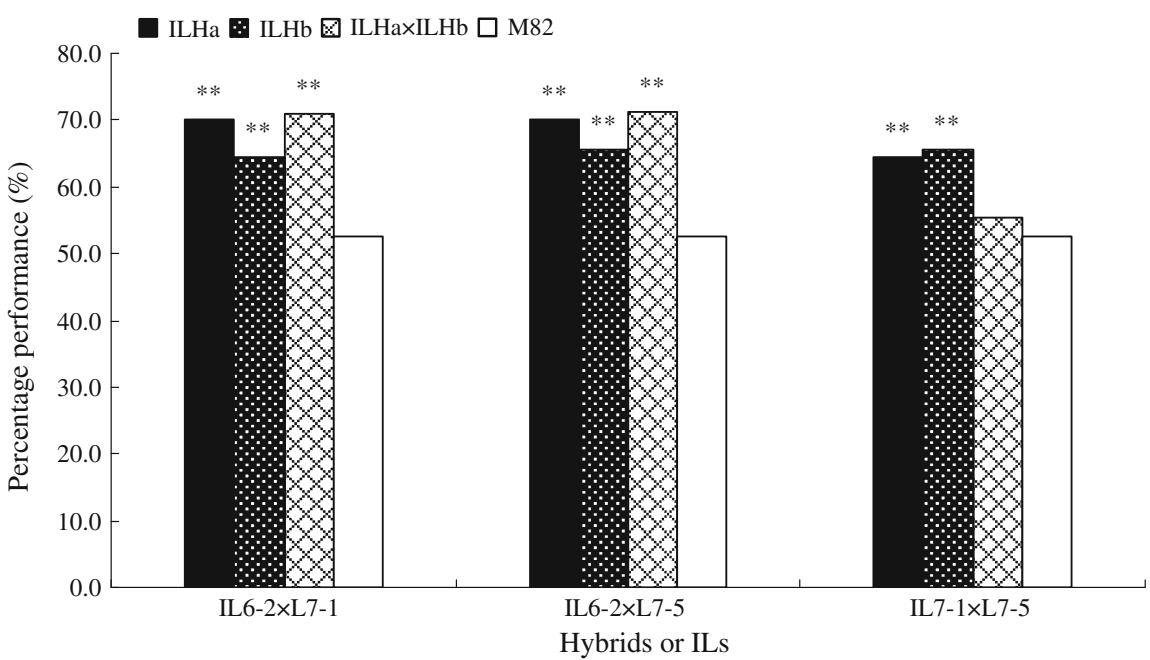

suggesting a negative epistatic effect of the combination of Stpq7a and Stpq7b (Fig. 3).

\section{Discussion}

Identification of QTLs for salt tolerance in the seedling stage

Two IL populations have been used to reveal quantitative trait loci for conferring salt tolerance in seedlings of tomato. Six and four independent experiments were conducted on the $S$. pennellii LA716 and $S$. lycopersicoides LA2951 IL populations. Although each experiment was done in a similar way low correlations between all experiments were observed, this was especially the case in the $S$. pennellii introgression library. This is probably due to differences in the plant physiology caused by the changing environmental conditions in the greenhouse. For example, experiment 3 and 4 for the $S$. pennellii LA716 population were conducted in the rainfall season, which affects the plant growth and development. Therefore we only used the experiments which were significantly correlated to analyze further for the detection of QTLs. The genetic background of the recurrent parent of the IL population is of importance to get significant differences, in our studies $S$. lycopersicum VF36 is more salt tolerant than M82. The large variation in circumstances makes that not all QTLs could be identified in all experiments and therefore repeated experiments were necessary. However the most robust QTLs, which make a stable and large contribution for salt tolerance, always showed a consistent performance for salt tolerance. For example, line IL6-2 harboring 
QTL Stpq6 showed a robust performance over all experiments.

Four and six major QTLs respectively from the two IL populations showed an unambiguous level of tolerance because lines harboring these QTLs presented a consistent salt tolerance in all analyzed experiments. However, some other QTLs were not confirmed by overlapping introgressions or by repetitions. The fact that they popped up in different experiments indicates that they do contain regions of interest which merit further research in the future. Thus, more experiments need to be done in order to confirm these QTLs. As the IL populations do not represent the entire genome, some QTLs for salt tolerance might not be detected.

In the S. lycopersicoides IL population, questionable QTLs are detected that are likely due to the fact that many heterozygous introgressions are present in this population. If an IL has heterozygous introgressions, a quarter of the offspring plants of this IL are without introgression resulting in an underestimation of the salt tolerance. A possibility to circumvent this problem is to select plants with the introgression by marker genotyping. Moreover, a limited seed production also restricts the possibility of doing many experiments to verify the questionable QTLs.

\section{Comparative analysis of QTLs for abiotic stress}

This study has revealed four unambiguous regions on chromosomes 6, 7 and 11 from S. pennellii LA716 and six regions on chromosomes 4, 6, 9 and 12 from S. lycopersicoides LA2951 with a significant effect on tomato salt tolerance in the seedling stage. In previous studies, eight QTLs for salt tolerance in the seedling stage were placed on chromosomes 1, 3, 5, 6, 9 and 11 in an interspecific backcross between a salt-sensitive S. lycopersicum NC84173 and a salttolerant $S$. pimpinellifolium accession LA722 (Foolad and Chen 1999). S. pennellii, S. lycopersicoides and S. pimpinellifolium are quite distantly related wild species. Molecular markers make it possible to compare map positions of QTLs coming from different species (Fig. 4). QTLs located on chromosome 6 are present in all the three populations. Stpq 6 derived from $S$. pennellii is flanked by markers TG365 and TG292, Stlq6 from S. lycopersicoides is flanked by markers TG297 and Adh-2, and one QTL from S. pimpinellifolium by markers CT285 and
Fig. 4 Integrated QTL map for salt tolerance during seed germination and seedling stage. Tomato map was draw based on Tomato-EXPEN 2000 (http://solgenomics.net/). Solid vertical bars indicate the approximate locations of QTLs derived from S. pennellii LA716 (Stpq) and S. lycopersicoides LA2951 $(S t l q)$ for salt tolerance during seedling stage. Hollow vertical bars indicate the approximate locations of QTLs previously identified from $S$. pimpinellifolium LA722 populations for salt tolerance during vegetative stage (renamed as Stvgq) (Foolad and Chen 1999; Foolad et al. 2001). Gray vertical bar indicate the approximate locations of QTLs previously identified from S. pennellii LA716 population for salt tolerance during seed germination (renamed as Stsgq) (Foolad et al. 1997). Dotted vertical bars indicated the approximate locations of QTLs derived from $S$. pimpinellifolium LA722 population for salt tolerance during seed germination (renamed as Stsgq) (Foolad et al. 1998)

TG477. Based on the tomato high density map (Tanksley et al. 1992), the region flanked by these markers could be limited to markers CT285 and Adh2 , in which they might be co-localized together. By the same manner, QTLs Stpq11 (TG557 and TG523) from S. pennellii and one QTL (TG497 and CT107) from $S$. pimpinellifolium co-localize on chromosome 11 and might be restricted between markers TG497 and TG651.

In addition, eight QTLs conferring salt tolerance during seed germination have been found with a $F_{2}$ population derived from $S$. pennellii LA716, which were located on chromosome 1, 2, 3, 7, 8, 9 and 12 (Foolad et al. 1997). Four QTLs originating from $S$. pennellii LA716 were mapped on chromosome 1, 3, 9 and 12 and seven QTLs from S. pimpinellifolium were located on chromosome 1, 2, 5, 7, 9 and 12 . Two regions on chromosome 7 and 9 are shared by the possibly co-localized QTLs. On chromosome 7, Stpq7b (TG418A and TG272A) and one QTL (CT52 and CT113) from $S$. pimpinellifolium might be restricted to markers TG113 and CT52. On chromosome 9, Stlq9b (TG186 and CT220) and one QTL (TG35 and Est-2) from S. pennellii might be between markers TG35 and Est-2. Salt tolerance during seed germination is independent of that during vegetative growth (Foolad 1999). Co-localization of some QTLs for salt tolerance during seed germination and the seedling stage would strengthen the evidence that the same genes might control the rate of seed germination and seedling growth. Crosstalk for response to adverse abiotic and biotic stressors may share the common pathway, in which secondary metabolisms make a significant contribution (Chinnusamy et al. 


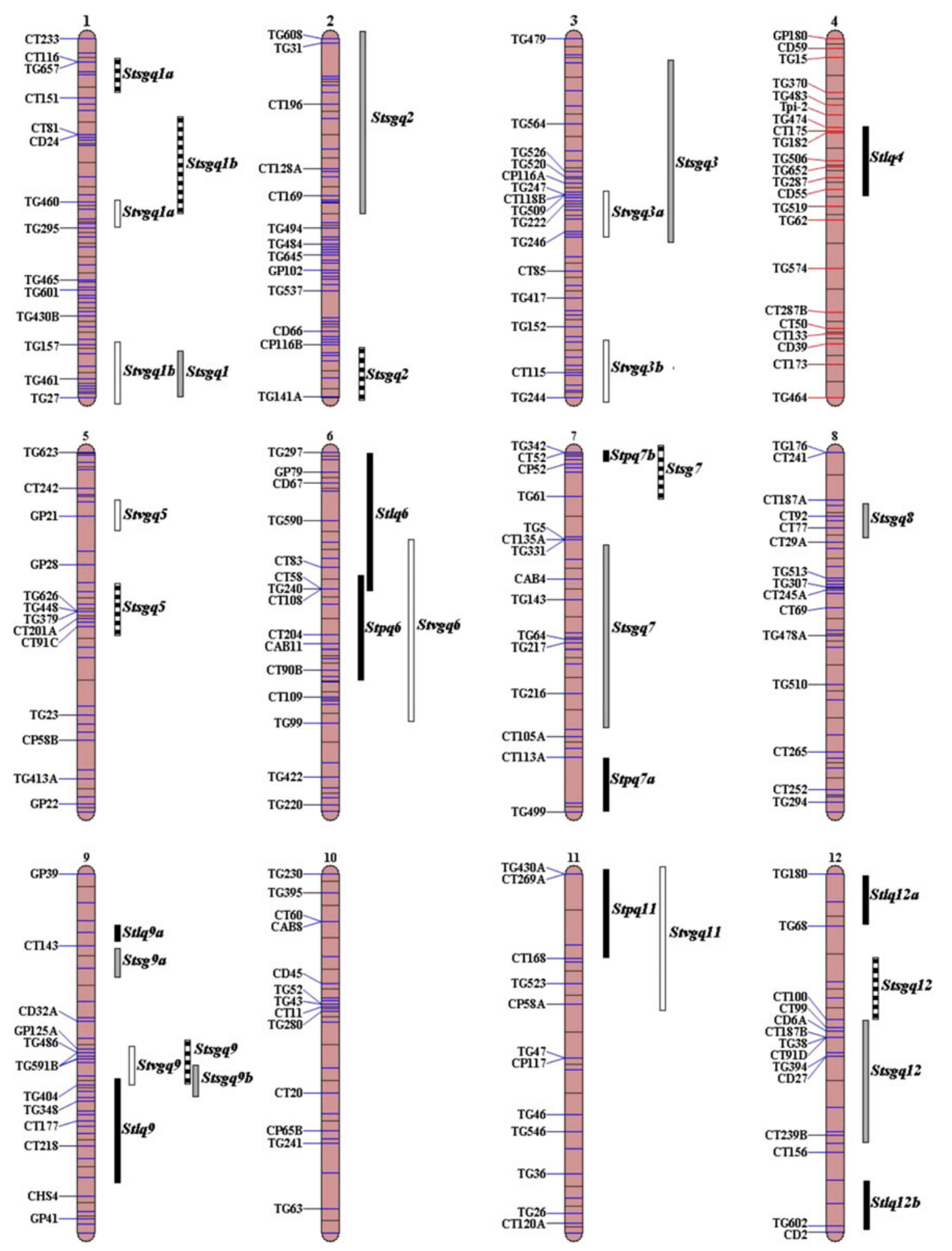


2004; Glombitza et al. 2004). Salt tolerance QTLs might also influence cold tolerance during seed germination (Foolad et al. 1999). One introgression (IL7-5-5) from S. pennellii LA716 causing drought tolerance (Gur and Zamir 2004) has shown a higher salt tolerance in the seedling stage in our study. In addition, more precise map positions will make it possible to speculate about co-localization of QTLs identified in different studies. For instance to look for co-localisation with the 49 QTLs for 19 traits under salt stress in two populations derived from $S$. pimpinellifolium and S. cheesmaniae. These QTLs were distributed over 11 chromosomes with the exception of chromosome 9 (Villalta et al. 2007).

Genetic effects of QTLs for salt tolerance

Phenotypic variation caused by QTLs is similar to variation for simple Mendelian inherited loci (Tanksley and Fulton 2007). Three ILs with major QTLs (Stpq6, Stpq7a and Stpq7b) have been used to make crosses in order to study dominance and additivity. All three QTLs were found to be semi-dominant or dominant. Combinations of introgression hybrids were made and the effect of the double heterozygotes was smaller than the sum of the effects of the corresponding single heterozygotes. The detected effect was non-additive or epistatic. This result was in agreement with previous studies, in which QTLs also showed less-than-additive effects (Eshed and Zamir 1996). The dominant nature of QTLs for salt tolerance in the seedling stage is positive for tomato hybrid breeding. In studies on the effects of QTLs on yield improvement under drought condition also dominant and even over-dominant effects were found (Gur and Zamir 2004). However, the combined effect of chromosomal regions from $S$. habrochaites LA1777 ILs acts mainly as epistatic effect and two interactions were antagonistic for morphological (plant height and leaf number at 5 weeks) and two ecophysiological (specific leaf area and time to wilting after experimental withholding of water) (Christopher and Leonie 2009). Epistasis is thought to play a key role in evolutionary processes and dynamics (Peters and Lively 1999; de Visser and Elena 2007; Christopher and Leonie 2009). It could provide more information to better understand the nature and pace of crop adaptation and species divergence. Hence, more QTLs in this paper still need to be combined to further know the genetic effects of QTLs especially for these with small effect. In addition, no evidence has been reported for the interaction of QTLs from the interspecies, for example, S. pennellii and S. lycopersicoides, until now. The results from this study provide the possibility to make hybrids with QTLs originating from two different sources.

Potential of pyramiding of QTLs for tomato salt tolerance

Pyramiding three independent yield-promoting segments (IL7-5-5, IL8-3 and IL9-2-5) from the drought tolerant $S$. pennellii LA716 has led to novel varieties with dramatically increased productivity under normal cultivation conditions but also in the presence of drought stress (Gur and Zamir 2004). We identified four and six QTLs for salt tolerance respectively from two wild species for the seedling stage. Combinations of QTLs are possible but for this it is necessary to reduce the introgression size because the linkage drag would also be larger and will most probably mask the effects. For example, IL6-2 showed the highest tolerance to salt in $S$. pennellii IL population; however it presented vigorous growth with very poor fruit setting as we observed in the field. Furthermore, combining QTLs in a single genetic background can lead to unexpected results. For example, less additive and overdominant effects have been found for yield and other quality traits (Eshed and Zamir 1996), and antagonistic effect was also observed for morphological and ecophysiological traits (Christopher and Leonie 2009). Generally these types of complex traits are affected by epistasis, locus heterogeneity, pleiotropy and their interaction with environments (Glazier et al. 2002; Coaker and Francis 2004; Semel et al. 2006; Causse et al. 2007).

In spite of all the research that has been conducted on tomato salt tolerance, it seems that the development of a salt tolerant cultivar is still far away even if transgenic strategies are being deployed (Cuartero et al. 2006). The main reason for this is the genetic and physiological complexity of salt tolerance (Cuartero and Fernandez-Munoz 1999; Flowers 2004; Cuartero et al. 2006). However the present study shows that improvement can be achieved albeit maybe at smaller steps and less fast then hoped for. 
Acknowledgments This project was funded by Key Laboratory of Horticultural Crops Genetic Improvement, Ministry of Agriculture of the People's Republic of China, the Royal Dutch Academy of Sciences (KNAW) and the Asian Facility (project AF01/CH/8 "Sino-Dutch Genomic Lab and Vegetable Research Center). The authors would like to thank Wang Baike, Wu Yuhui, Su Caixia and Fan Weiqiang for their kind help during the experiments.

Open Access This article is distributed under the terms of the Creative Commons Attribution Noncommercial License which permits any noncommercial use, distribution, and reproduction in any medium, provided the original author(s) and source are credited.

\section{References}

Astua-Monge G, Minsavage GV, Stall RE, Vallejos CE, Davis MJ, Jones JB (2000) Xv4-vrxv4: a new gene-for-gene interaction identified between Xanthomonas campestris pv. vesicatoria race T3 and the wild tomato relative Lycopersicon pennellii. Mol Plant Microbe In 13:1346-1355

Bretó MP, Aśins MJ, Carbonell EA (1994) Salt tolerance in Lycopersicon species. III. Detection of quantitative trait loci by means of molecular markers. Theor Appl Genet 88:395-401

Burns G, Billard TC, Matsui KM (1990) Salinity threat to Upper Egypt. Nature 344:25

Canady MA, Meglic V, Chetelat RT (2005) A library of Solanum lycopersicoides introgression lines in cultivated tomato. Genome 48:685-697

Causse M, Chaib J, Lecomte L, Buret M, Hospital F (2007) Both additivity and epistasis control the genetic variation for fruit quality traits in tomato. Theor Appl Genet 115:429-442

Chinnusamy V, Schumaker K, Zhu J-K (2004) Molecular genetic perspectives on cross-talk and specificity in abiotic stress signalling in plants. J Exp Bot 55:225-236

Christopher DM, Leonie CM (2009) Antagonistic epistasis for ecophysiological trait differences between Solanum species. New Phytol 183:789-802

Coaker GL, Francis DM (2004) Mapping, genetic effects, and epistatic interaction of two bacterial canker resistance QTLs from Lycopersicon hirsutum. Theor Appl Genet 108:1047-1055

Costa J, Nuez F, Anastasio G, Palomares G (1990) The use Lycopersicon cheesmanii in breeding for salt-tolerant tomatoes. Rep Tomato Genet Coop 40:9-10

Cuartero J, Fernandez-Munoz R (1999) Tomato and salinity. Sci Hortic-Amsterdam 78:83-125

Cuartero J, Bolarin MC, Asins MJ, Moreno V (2006) Increasing salt tolerance in the tomato. J Exp Bot 57:1045-1058

de Visser J, Elena SF (2007) The evolution sex: empirical insights into the roles of epistasis and drift. Nat Rev Genet 8:139-149

Elshourbagy MN, Ahmed AM (1975) Responses of 2 varieties of tomato to abrupt and gradual short-period sodiumchloride exposure. Plant Soil 42:255-271
Epstein E (1972) Physiological genetics of plant nutrition. In: Epstein E (ed) Mineral nutrition of plants: principles and perspectives. Wiley, New York, pp 325-344

Eshed Y, Zamir D (1995) An introgression line population of Lycopersicon pennellii in the cultivated tomato enables the identification and fine mapping of yield-associated QTL. Genetics 141:1147-1162

Eshed Y, Zamir D (1996) Less-than-additive epistatic interactions of quantitative trait loci in tomato. Genetics 143:1807-1817

Finkers R, van Heusden AW, Meijer-Dekens F, van Kan JAL, Maris P, Lindhout P (2007) The construction of a Solanum habrochaites LYC4 introgression line population and the identification of QTLs for resistance to Botrytis cinerea. Theor Appl Genet 114:1071-1080

Flowers TJ (2004) Improving crop salt tolerance. J Exp Bot 55:307-319

Foolad MR (1997) Genetic basis of physiological traits related to salt tolerance in tomato, Lycopersicon esculentum Mill. Plant Breed 116:53-58

Foolad MR (1999) Comparison of salt tolerance during seed germination and vegetative growth in tomato by QTL mapping. Genome 42:727-734

Foolad MR (2004) Recent advances in genetics of salt tolerance in tomato. Plant Cell Tissue Organ Cult 76:101-119

Foolad MR, Chen FQ (1999) RFLP mapping of QTLs conferring salt tolerance during the vegetative stage in tomato. Theor Appl Genet 99:235-243

Foolad MR, Chen FQ, Lin GY (1998) RFLP mapping of QTLs conferring salt tolerance during germination in an interspecific cross of tomato. Theor Appl Genet 97:1133-1144

Foolad MR, Lin GY (1997) Genetic potential for salt tolerance during germination in Lycopersicon species. Hortscience 32:296-300

Foolad MR, Stoltz T, Dervinis C, Rodriguez RL, Jones RA (1997) Mapping QTLs conferring salt tolerance during germination in tomato by selective genotyping. Mol Breed 3:269-277

Foolad MR, Lin GY, Chen FQ (1999) Comparison of QTLs for seed germination under non-stress, cold stress and salt stress in tomato. Plant Breed 118:167-173

Foolad MR, Zhang LP, Lin GY (2001) Identification and validation of QTLs for salt tolerance during vegetative growth in tomato by selective genotyping. Genome 44:444-454

Francis DM, Kabelka E, Bell J, Franchino B, Clair DS (2001) Resistance to bacterial canker in tomato (Lycopersicon hirsutum LA407) and its progeny derived from crosses to L. esculentum. Plant Dis 85:1171-1176

Ghassemi F, Jakeman AJ, Nix HA (1995) Salinisation of land and water resources: human causes, extent, management. UNSW Press

Glazier AM, Nadeau JH, Aitman TJ (2002) Finding genes that underlie complex traits. Science 298:2345-2349

Glombitza S, Dubuis P-h, Thulke O, Welzl G, Bovet L, Götz M, Affenzeller M, Geist B, Hehn A, Asnaghi C, Ernst D, Seidlitz H, Gundlach H, Mayer K, Martinoia E, Werckreichhart D, Mauch F, Schäffner A (2004) Crosstalk and differential response to abiotic and biotic stressors reflected at the transcriptional level of effector genes from secondary metabolism. Plant Mol Biol 54:817-835 
Greenway H, Munns R (1980) Mechanisms of salt tolerance in nonhalophytes. Annu Rev Plant Physiol 31:149-190

Gur A, Zamir D (2004) Unused natural variation can lift yield barriers in plant breeding. PLoS Biol 2:e245

Hassan AA, Al-Aflfl MA, Matsuda K, Itanl S (1990) Screening for salinity tolerance in the genus Lycopersicon. Rep Tomato Genet Coop 40:14-15

Johnson DW, Smith SE, Dobrenz AK (1992) Genetic and phenotypic relationships in response to $\mathrm{NaCl}$ at different developmental stages in alfalfa. Theor Appl Genet 83:833-838

Lauchli A, Epstein E (1990) Plant response to saline and sodic conditions. In: Tanji KK (ed) Agricultural salinity assessment and management manual. American Society of Civil Engineerings, New York, pp 113-137

Maas EV (1986) Salt tolerance of plants. Appl Agric Res $1: 12-26$

Mao R, Fitzpatrick R, Liu X, Davies P (2002) Chemical properties of selected soils from the North China Plain. In: Mcvicar TR, Li R, Walker J, Fitzpatrick RW, Liu CM (eds) Regional water and soil assessment for managing sustainable agriculture in China and Australia. Australian Centre for International Agricultural Research, Canberra

Monforte AJ, Tanksley SD (2000) Development of a set of near isogenic and backcross recombinant inbred lines containing most of the Lycopersicon hirsutum genome in a L. esculentum genetic background: a tool for gene mapping and gene discovery. Genome 43:803-813

Monforte AJ, Asins MJ, Carbonell EA (1996) Salt tolerance in Lycopersicon species IV. Efficiency of marker-assisted selection for salt tolerance improvement. Theor Appl Genet 93:765-772

Monforte AJ, Asins MJ, Carbonell EA (1997a) Salt tolerance in Lycopersicon species. V. Does genetic variability at quantitative trait loci affect their analysis? Theor Appl Genet 95:284-293

Monforte AJ, Asins MJ, Carbonell EA (1997b) Salt tolerance in Lycopersicon species.VI. Genotype by salinity interaction in quantitative trait loci detection: constitutive and response QTLs. Theor Appl Genet 95:706-713

Monforte AJ, Asins MJ, Carbonell EA (1999) Salt tolerance in Lycopersicon spp. VII. Pleiotropic action of genes controlling earliness on fruit yield. Theor Appl Genet 98: 593-601

Pan Q, Liu Y-S, Budai-Hadrian O, Sela M, Carmel-Goren L, Zamir D, Fluhr R (2000) Comparative genetics of nucleotide binding site-leucine rich repeat resistance gene homologues in the genomes of two dicotyledons: tomato and arabidopsis. Genetics 155:309-322

Peters AD, Lively CM (1999) The red queen and fluctuating epistatic: a population genetic analysis of antagonistic coevolution. Am Nat 154:393-405

Rousseaux MC, Jones CM, Adams D, Chetelat R, Bennett A, Powell A (2005) QTL analysis of fruit antioxidants in tomato using Lycopersicon pennellii introgression lines. Theor Appl Genet 111:1396-1408

Rush DW, Epstein E (1976) Genotypic responses to salinity: differences between salt-sensitive and salt-tolerant genotypes of the tomato. Plant Physiol 57:162-166

Saranga Y, Cahaner A, Zamir D, Marani A, Rudich J (1992) Breeding tomatoes for salt tolerance: inheritance of salt tolerance and related traits in interspecific populations. TAG Theor Appl Genet 84:390-396

Semel Y, Nissenbaum J, Menda N, Zinder M, Krieger U, Issman N, Pleban T, Lippman Z, Gur A, Zamir D (2006) From the Cover: overdominant quantitative trait loci for yield and fitness in tomato. Proc Natl Acad Sci USA 103:12981-12986

Shannon M (1985) Principles and strategies in breeding for higher salt tolerance. Plant Soil 89:227-241

Tanksley SD, Ganal MW, Prince JP, de-Vicente MC, Bonierbale MW, Broun P, Fulton TM, Giovannoni JJ, Grandillo S, Martin GB, Messeguer R, Miller JC, Miller L, Paterson AH, Pineda O, Roder MS, Wing RA, Wu W, Young ND (1992) High density molecular linkage maps of the tomato and potato genomes. Genetics 132:1141-1160

Tanksley S, Fulton T (2007) Dissecting quantitative trait variation-examples from the tomato. Euphytica 154:365-370

Tieman DM, Zeigler M, Schmelz EA, Taylor MG, Bliss P, Kirst M, Klee HJ (2006) Identification of loci affecting flavour volatile emissions in tomato fruits. J Exp Bot 57:887-896

Villalta I, Bernet GP, Carbonell EA, Asins MJ (2007) Comparative QTL analysis of salinity tolerance in terms of fruit yield using two solanum populations of F-7 lines. Theor Appl Genet 114:1001-1017

Zhang K, Yu Z, Li X, Zhou W, Zhang D (2007) Land use change and land degradation in China from 1991 to 2001. Land Degrad Dev 18:209-219 